\title{
High-throughput genome sequencing of two Listeria monocytogenes clinical isolates during a large foodborne outbreak
}

\author{
Matthew W Gilmour ${ }^{1,2 *}$, Morag Graham ${ }^{1,2}$, Gary Van Domselaar ${ }^{1}$, Shaun Tyler $^{1}$, Heather Kent ${ }^{1}$, Keri M Trout-Yakel ${ }^{1}$, \\ Oscar Larios ${ }^{2}$ Vanessa Allen ${ }^{3}$, Barbara Lee ${ }^{4}$, Celine Nadon ${ }^{1,2}$
}

\begin{abstract}
Background: A large, multi-province outbreak of listeriosis associated with ready-to-eat meat products contaminated with Listeria monocytogenes serotype 1/2a occurred in Canada in 2008. Subtyping of outbreakassociated isolates using pulsed-field gel electrophoresis (PFGE) revealed two similar but distinct Ascl PFGE patterns. High-throughput pyrosequencing of two L. monocytogenes isolates was used to rapidly provide the genome sequence of the primary outbreak strain and to investigate the extent of genetic diversity associated with a change of a single restriction enzyme fragment during PFGE.

Results: The chromosomes were collinear, but differences included 28 single nucleotide polymorphisms (SNPs) and three indels, including a $33 \mathrm{kbp}$ prophage that accounted for the observed difference in Ascl PFGE patterns. The distribution of these traits was assessed within further clinical, environmental and food isolates associated with the outbreak, and this comparison indicated that three distinct, but highly related strains may have been involved in this nationwide outbreak. Notably, these two isolates were found to harbor a $50 \mathrm{kbp}$ putative mobile genomic island encoding translocation and efflux functions that has not been observed in other Listeria genomes.
\end{abstract}

Conclusions: High-throughput genome sequencing provided a more detailed real-time assessment of genetic traits characteristic of the outbreak strains than could be achieved with routine subtyping methods. This study confirms that the latest generation of DNA sequencing technologies can be applied during high priority public health events, and laboratories need to prepare for this inevitability and assess how to properly analyze and interpret whole genome sequences in the context of molecular epidemiology.

\section{Background}

Listeria monocytogenes is a Gram-positive, facultative intracellular bacterial pathogen that can cause severe disease in humans, other mammals and birds [1]. Human listeriosis is relatively rare despite our likely frequent encounters with L. monocytogenes, which is ubiquitously present in the environment (including water, soil, vegetation), farm and rural environments, and urban environments [2-6]. The vast majority of human listeriosis is foodborne and the most commonly implicated vehicles are ready-to-eat food products such as meat, dairy, seafood, and fresh produce that are

\footnotetext{
* Correspondence: Matthew_Gilmour@phac-aspc.gc.ca
${ }^{1}$ National Microbiology Laboratory, Public Health Agency of Canada,

* Correspondence: Matthew_Gilmour@phac-aspc.gc.ca
${ }^{1}$ National Microbiology Laboratory, Public Health Agency of Canada, Winnipeg, MB, Canada
}

(c) 2010 Gilmour et al; licensee BioMed Central Ltd. This is an Open Access article distributed under the terms of the Creative Commons Attribution License (http://creativecommons.org/licenses/by/2.0), which permits unrestricted use, distribution, and reproduction in any medium, provided the original work is properly cited. cessing facilities and food products due to cross-contamination with environmental sources or from the feces of food production animals. L. monocytogenes can persist within food processing environments for long periods of time, due in part to its ability to grow at wide-ranging temperatures and $\mathrm{pH}\left(0.4^{\circ} \mathrm{C}\right.$ to $45^{\circ} \mathrm{C}, \mathrm{pH} 4$ to 9.6) and the ability to form biofilms promoting adherence to food processing surfaces [8-11]. The persistence of a single subtype of $L$. monocytogenes in processing facilities or on equipment has been reported from several months to more than 10 years [12,13].

Given the widespread occurrence of L. monocytogenes, subtyping of clinical and food isolates is required to establish epidemiologic links during routine surveillance, 
outbreak investigations, and for source tracking. There are 13 known serotypes of $L$. monocytogenes but the vast majority of human disease cases are caused by strains belonging to serotypes $4 \mathrm{~b}, 1 / 2 \mathrm{a}$, and $1 / 2 \mathrm{~b}$, severely limiting the utility of this subtyping method for differentiating L. monocytogenes [14]. Large clonal outbreaks owing to contaminated food sources such as coleslaw, milk, cheese, hot dogs and deli meats, have been predominately caused by serotypes $4 \mathrm{~b}$ and $1 / 2 \mathrm{a}$ strains [15]. Accordingly, additional subtyping methods are required to better characterize outbreak isolates. Several molecular subtyping methods have been developed and applied to L. monocytogenes, including pulsed-field gel electrophoresis (PFGE), ribotyping, multilocus variable-number tandem repeat analysis (MLVA), and sequence-based subtyping [14,16,17]. PFGE has been adopted by PulseNet as the internationally standardized method for molecular subtyping of L.monocytogenes and has been essential in the detection and investigation of listeriosis outbreaks in Canada and worldwide [18-20].

DNA sequencing has enabled analyses of $L$. monocytogenes genomes and furthered the understanding of this pathogen's biology and phylogeny. Comparative analyses of genome sequences have elucidated the genetic differences between $L$. monocytogenes serotypes, the acquisition and evolution of virulence and pathogenic traits among Listeria spp., and the genetic basis underlying the unique survival and growth characteristics of $L$. monocytogenes [21-23]. Genome sequencing has also permitted the development of multi-locus sequence typing (MLST) protocols, which in combination with other typing methods, have validated three evolutionary lineages for L. monocytogenes [24-29]. The lineages reflect the serotype distribution, with serotypes $1 / 2 \mathrm{~b}, 3 \mathrm{~b}$ and $4 \mathrm{~b}$ segregating to lineage I and serotypes $1 / 2 \mathrm{a}$ and $1 / 2 \mathrm{c}$ segregating to lineage II. Risk assessments based upon genetic lineages have suggested that $L$. monocytogenes subtypes may have unique ecological niches and may also differ in their pathogenic potential or host adaptations [30,31].

The majority of available bacterial genome sequences have been generated using the Sanger chain termination sequencing chemistries. Although this technology was instrumental in the emergence of the field of genomics, it is time and resource intensive [32,33]. Several postSanger sequencing technologies (also referred to as next-generation sequencing technologies) have since been developed that enable extremely rapid wholegenome sequencing and a broader application of comparative genomics $[33,34]$. The high-throughput pyrosequencing method commercialized as the 454 or GS FLX ${ }^{\text {sm }}$ platform has been applied for rapidly determining the genome sequences of bacterial isolates.
L. monocytogenes serotype $1 / 2$ a caused a nationwide outbreak of listeriosis associated with ready-to-eat meat products in Canada during the summer of 2008. The outbreak resulted in 22 deaths and at least 57 illnesses. Whereas the majority of outbreak-associated isolates (human clinical and food isolates) had an indistinguishable AscI PFGE pattern, one clinical isolate from Ontario and several isolates from the affected food production facility exhibited an AscI PFGE pattern that differed by a single restriction enzyme fragment compared to the primary outbreak strain. We report herein the first real-time application of whole-genome sequencing during an active listeriosis outbreak investigation. Highthroughput pyrosequencing was applied to characterize two outbreak-associated isolates of L. monocytogenes in order to obtain a thorough genetic characterization of the outbreak strains and to determine the genetic basis for the single $A s c \mathrm{I}$ restriction fragment change.

\section{Results and Discussion}

Primary outbreak isolate harbors unique plasmid pLM5578 and prophage $\varphi$ LMC1

Public health responses to foodborne outbreaks require bacterial subtyping data to definitively link affected individuals with contaminated food sources and other suspected patients. The genetic relatedness between clinical and food isolates is routinely determined using methods such as PFGE, however, with the latest generation of DNA sequencing technologies it is theoretically possible to now determine the complete genetic blueprint of bacterial isolates within the scope of an outbreak. In this study, draft genome sequences suitable for comparative analysis between outbreak isolates and to reference genomes were available within three days. These data allowed for discovery of novel prophage and genomic islands, and the subsequent sequence closure and the confirmation of sequence variants allowed for annotation of polymorphisms and other traits associated with micro-diversity.

Clinical isolate $08-5578$ was selected as the reference outbreak strain (serotype 1/2a; PFGE patterns LMACI.0040 and LMAAI.0001; Table 1) and clinical isolate 08-5923 differed only in the AscI restriction pattern (LMACI.0001; Fig. 1). High-throughput pyrosequencing was performed on both isolates and closed circular chromosomal sequences were obtained for each isolate (Table 2; Fig. 2). A $77 \mathrm{kbp}$ contig present in the 08-5578 sequence assembly but absent in 08-5923 was identified as a circular plasmid and designated pLM5578 (Table 2). Comparison of the chromosomal sequences for isolates 08-5578 and 08-5923 with publicly available Listeria spp. genomes (Fig. 3A) and with select loci used for MLST (Fig. 3B) indicated that these isolates were 
Table 1 Bacterial isolates used in this study and results of PCR-based screening assays.

\begin{tabular}{|c|c|c|c|c|c|c|c|c|c|c|c|c|}
\hline \multirow[b]{2}{*}{ Isolate No. } & \multirow[b]{2}{*}{ Source } & \multirow[b]{2}{*}{ Specimen type $^{a}$} & \multirow[b]{2}{*}{ Serotype } & \multicolumn{2}{|c|}{$\begin{array}{l}\text { Pulsed-field gel } \\
\text { electrophoresis }\end{array}$} & \multicolumn{2}{|c|}{ Prophage $\varphi \mathrm{LMC}^{\mathrm{b}}$} & \multicolumn{2}{|c|}{ pLM5578 } & \multirow[b]{2}{*}{ buk } & \multirow[b]{2}{*}{$g l t X^{d}$} & \multirow[b]{2}{*}{ SNPs ${ }^{\mathrm{e}}$} \\
\hline & & & & $\overline{A s c l}$ & Apal & terminase & tail protein & virD4 & fic & & & \\
\hline $08-5578$ & Human & Blood & $1 / 2 a$ & LMACI.0040 & LMAAI.0001 & + & + & + & + & FS & $-21 b p$ & 1 \\
\hline 08-5923 & Human & Blood & $1 / 2 \mathrm{a}$ & LMACI.0001 & LMAAI.0001 & - & - & - & - & WT & WT & 27 \\
\hline $08-6040$ & Food & RTE meat & $1 / 2 \mathrm{a}$ & LMACI.0040 & LMAAI.0001 & + & + & + & + & FS & $-21 b p$ & 1 \\
\hline $08-6055$ & Food & RTE meat & $1 / 2 \mathrm{a}$ & LMACI.0040 & LMAAI.0001 & + & + & - & - & FS & $-21 b p$ & 1 \\
\hline 08-6135 & Human & CSF & $1 / 2 \mathrm{a}$ & LMACI.0040 & LMAAI.0001 & + & + & + & + & FS & $-21 b p$ & 1 \\
\hline $08-6567$ & Environment & Food processing & $1 / 2 \mathrm{a}$ & LMACI.0040 & LMAAI.0001 & + & + & + & + & FS & $-21 b p$ & 1 \\
\hline $08-6061$ & Food & RTE meat & $1 / 2 \mathrm{a}$ & LMACI.0040 & LMAAI.0001 & + & + & + & + & FS & $-21 b p$ & 1 \\
\hline $08-6421$ & Human & Blood & $1 / 2 \mathrm{a}$ & LMACI.0040 & LMAAI.0001 & + & + & + & + & FS & $-21 b p$ & 1 \\
\hline 08-5828 & Human & Blood & $1 / 2 \mathrm{a}$ & LMACI.0040 & LMAAI.0001 & + & + & - & - & FS & $-21 b p$ & 1 \\
\hline 08-7374 & Environment & Food processing & $1 / 2 \mathrm{a}$ & LMACI.0001 & LMAAI.0001 & - & - & - & - & FS & WT & 0 \\
\hline 08-7376 & Environment & Food processing & $1 / 2 \mathrm{a}$ & LMACI.0001 & LMAAI.0001 & - & - & - & - & FS & WT & 0 \\
\hline 08-7381 & Environment & Food processing & $1 / 2 \mathrm{a}$ & LMACI.0001 & LMAAI.0001 & - & - & - & - & FS & WT & 0 \\
\hline 08-7382 & Environment & Food processing & $1 / 2 \mathrm{a}$ & LMACI.0001 & LMAAI.0001 & - & - & - & - & FS & WT & 0 \\
\hline
\end{tabular}

a. 'RTE', ready to eat; 'CSF', cerebrospinal fluid

b. ' + ', amplicon of expected size detected using PCR using oligonucleotides described in Additional file 6; ' - ', no amplicon detected

c. 'FS', frameshift resulting in a truncated coding sequence encoding butyrate kinase; 'WT', wild type. Confirmed by Sanger-based DNA sequencing of amplicons generated by high fidelity PCR.

d. 'WT', wild type; '-21 bp', in-frame deletion of 7 codons. Confirmed by Sanger-based DNA sequencing of amplicons generated by PCR.

e. Number of SNP's relative to the hypothetical last common ancestor presented in Fig. 6 . Sanger-based DNA sequence confirmation of SNPs was completed after PCR amplification using oligonucleotides described in Additional file 6.

members of evolutionary lineage II and clonal complex 8 (discussed further below).

The AscI restriction patterns of 08-5578 and 08-5923 were indistinguishable, except for a single band shift of approximately $32 \mathrm{kbp}$ (from $476 \mathrm{kbp}$ in $08-5578$ to 444 kbp in 08-5923; Fig. 1). Accordingly, comparative sequence alignment revealed a $33 \mathrm{kbp}$ contiguous region integrated adjacent to (but not disrupting) the tRNA-Ser gene that was unique to 08-5578 and encoding several putative bacteriophage-related coding sequences (designated $\varphi$ LMC1) (Fig. 4). BLAST analyses indicated that this prophage was unique among sequenced Listeria genomes, although it was comprised of coding sequences similar to determinants from several known phages associated with Gram-positive microbes, including L. monocytogenes phages A006, A118 and B025 (see Additional file 1). The presence of prophage $\varphi \mathrm{LMC1}$ accounted for the $A s c$ I restriction pattern difference between isolates 08-5578 and 08-5923.

The extrachromosomal circular plasmid (pLM5578) harbored in isolate 08-5578 encoded putative determinants for replication, partitioning, heavy metal resistance and DNA translocation (Fig. 5a, and Additional file 2). Many of these features were homologous to sequences encoded by plasmids from L. innocua (pLI100), $L$. monocytogenes serotype $4 \mathrm{~b}$ isolate H7858 (pLM80) and Bacillus anthracis (pXO2), including a replication and regulation control center (pLM5578_17 - 20). Two regions of pLM5578 were related to heavy metal resistance, including a transposon-associated $\operatorname{cadA}$ that exhibited high sequence identity to pLI100. A second, distinct region unique to pLM5578 was comprised of cadA (second copy) and cadC genes, with the latter encoding a cadmium-efflux ArsR-family regulatory accessory protein (repressor) homolog. Resistance to the heavy metal cadmium has been recently discovered to be associated with resistance to quaternary ammonium compounds (sanitizers), which may contribute to $L$. monocytogenes persistence in food production facilities [35]. Notably, several coding sequences exhibited sequence similarity to type IV secretion systems (T4SS), including DNA processing (virD2), DNA coupling (virD4) and membrane channel formation (virB1, -B4, $-B 5,-B 6,-B 11$ ) (see Additional file 2). Additional predicted membrane-associated proteins were present within this region, and all coding sequences were oriented in the same direction (Fig. 5A), which is consistent with the operon-style organization of most known T4SS. Varying degrees of similarity between pLI100, pLM80 and pXO2 plasmids have already been established [21], and our data further support a chimeric nature for Listeria plasmids.

\section{pLM5578 and $\varphi$ LMC1 exhibit non-homogeneous distribution within a wider panel of outbreak-associated isolates}

During the outbreak, serotype $1 / 2$ a L. monocytogenes isolates were recovered from clinical samples, contaminated food products and the food processing environment that shared the two AscI PFGE patterns observed 




for the sequenced isolates (Table 1). To determine the distribution of $\varphi$ LMC1 and pLM5578 amongst outbreak-associated isolates, PCR-based screening was conducted by targeting $\varphi \mathrm{LMC} 1$ loci encoding a putative phage terminase large subunit and phage tail tape measure protein, and pLM5578 loci encoding virD4 and fic (Table 1). All isolates with AscI pattern LMACI.0001 lacked the $\varphi \mathrm{LMC} 1$ determinants by PCR, confirming that this novel sequence insertion accounts for the
Table 2 General genomic characteristics of Listeria monocytogenes isolates $08-5578,08-5923$, and plasmid pLM5578.

\begin{tabular}{lccc}
\hline & $\mathbf{0 8 - 5 5 7 8}$ & pLM5578 & $\mathbf{0 8 - 5 9 2 3}$ \\
\hline Genome size (bp) & 3032 288 & 77054 & 2999054 \\
G/C content & 37.96 & 36.59 & 37.96 \\
No. of predicted coding sequences & 3010 & 79 & 2966 \\
Average length of coding & 900 & 833 & 903 \\
sequences (bp) & & & \\
Coding percentage & 89.3 & 85.4 & 89.3 \\
rRNA loci & 13 & 0 & 13 \\
Bacteriophage & 3 & 0 & 2 \\
\hline
\end{tabular}

restriction enzyme pattern shift relative to PFGE pattern LMACI.0040. Bacteriophage insertions have previously been recognized as contributing to macromolecular genetic diversity between related outbreak-associated $L$. monocytogenes strains $[12,36]$.

The PCR screening assays for plasmid determinants confirmed that pLM5578 was absent in isolate 08-5923, and this plasmid was also absent in other outbreakrelated isolates (independent of PFGE profile), including one clinical isolate (Table 1). The sequence of pLM5578 revealed an absence of $A s c \mathrm{I}$ restriction sites and presence of a single ApaI restriction site, but this element did not contribute to the PFGE patterns resulting from these enzymes. In contrast, plasmid pLM80 (containing a single ApaI recognition site) had been reported as visible in ApaI PFGE digests [36]. Just as a variable presence of plasmid pLM5578 was observed in this Canadian outbreak, plasmid pLM80 was sporadically present in isolates during the 1998-99 multi-state serotype 4b frankfurter USA outbreak [36]. Lack of stable vertical transmission of pLM5578 during the outbreak or laboratory culture (despite the presence of a partitioning determinant, pLM5578_15) might account for plasmid absence. Alternatively, pLM5578 may have been carried only in a subset of L. monocytogenes strains that subsequently caused the outbreak. Presence of determinants related to bacterial conjugation (Fig. 5A) further confounds any speculation on the transmission of this plasmid.

\section{Whole genome comparisons enable construction of an evolutionary model of the outbreak isolates}

The genomes of 08-5578 and 08-5923 were collinear, and with the exception of the prophage and plasmid unique to 08-5578, all genetic diversity was accounted for by 2 short indels and 28 confirmed SNPs. The two indels included a single $\mathrm{C} / \mathrm{T}$ base pair insertion in $08-5578$ that introduced a frameshift truncation into coding sequence LM5578_1509 (buk, encoding a putative butyrate kinase). Secondly, there was a 21 bp (7 codon) in-frame deletion 


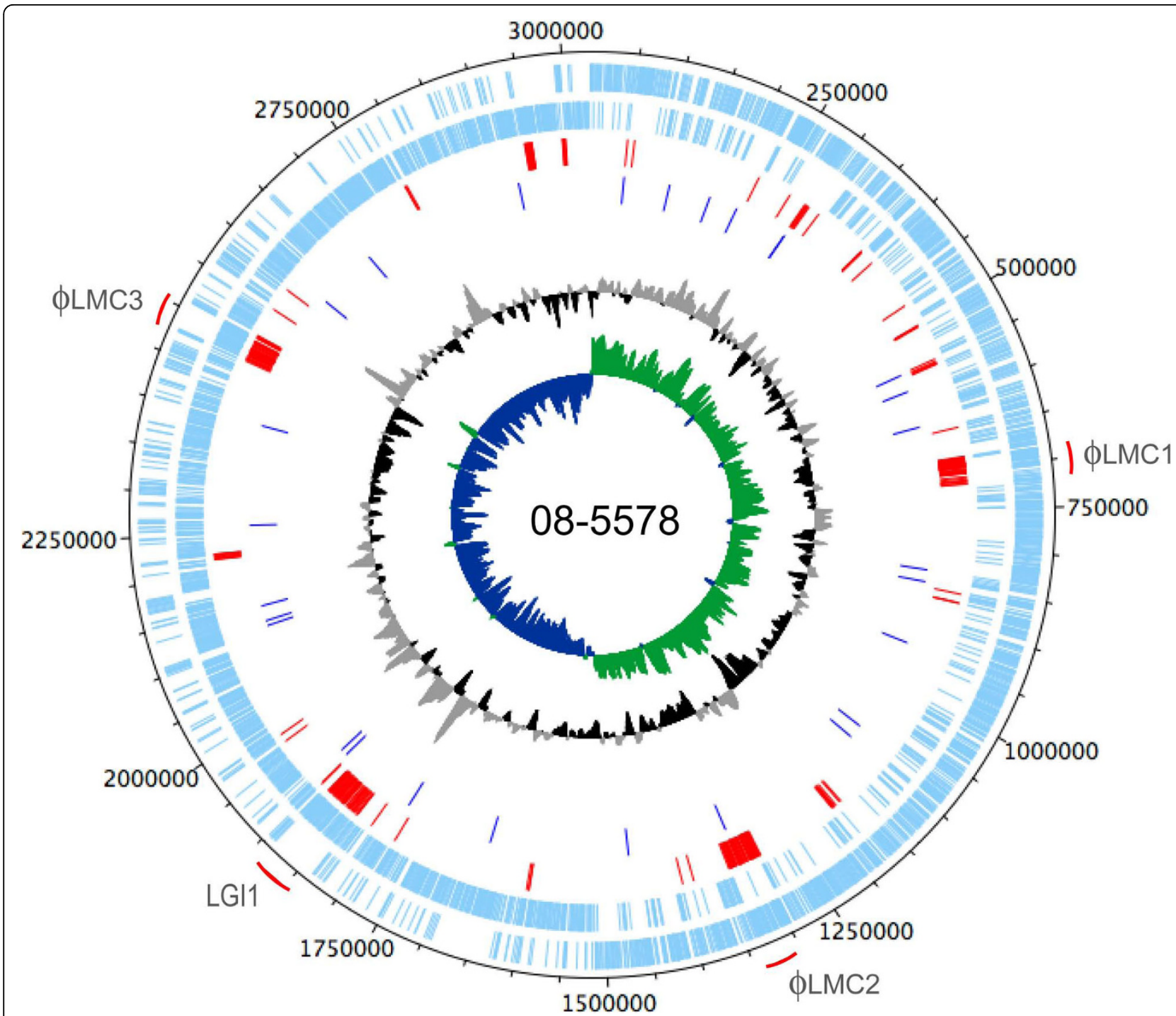

Figure 2 Circular map and genetic features of Listeria monocytogenes isolate $\mathbf{0 8 - 5 5 7 8 . ~ T h e ~ o u t e r ~ r i n g ~ d e n o t e s ~ g e n e t i c ~ c o o r d i n a t e s , ~ a n d ~}$ prophage and the novel $50 \mathrm{kbp}$ Listeria genomic island (LGI1) are indicated in grey text. Prophage $\varphi \mathrm{LMC1}$ is not encoded within isolate 08 5923. Light blue bars ( $2^{\text {nd }}$ and $3^{\text {rd }}$ rings) denote coding sequences on the positive and negative strands, respectively. Red bars ( $4^{\text {th }}$ ring) denote those coding sequences present in 08-5578 but absent in the genome sequence of strain EGDe. Dark blue bars $\left(5^{\text {th }}\right.$ ring) indicate confirmed single nucleotide polymorphisms between isolate $08-5578$ and 08-5923. The black/grey and blue/green plots indicate $\mathrm{G}+\mathrm{C}$ content and $\mathrm{G}+\mathrm{C}$ skew, respectively.

in the gltX gene (LM5578_0279) of 08-5578 encoding a putative glutamyl-tRNA synthetase. DNA sequencing confirmed that this $g l t X$ deletion was present in all examined LMACI.0040 isolates but that a wild type allele was present in all isolates typed as LMACI.0001 (Table 1). Alternatively, a wild type buk gene was only observed in isolate 08-5923 and a truncated butyrate kinase was encoded in all other isolates, independent of PFGE pattern (Table 1). Directed PCR and DNA sequencing of the SNP sites within the panel of clinical, food and environmental isolates was also performed (Table 1). Of the 28 SNPs, 27 were only present in isolate 08-5923. The singular remaining non-coding SNP was observed in each of LMACI.0040 isolates (at intergenic coordinate 2691224 of 08-5578) but was absent in all of the LMACI.0001 isolates, including 08-5923.

The 27 SNPs observed in the genome of clinical isolate 08-5923 included 20 non-synonymous, 5 synonymous and 2 intergenic mutations (Table 3). Such a predominance of non-synonymous changes suggests that isolate 08-5923 was under strong positive selection for functional divergence rather than purifying selection (wherein synonymous exceed non-synonymous mutation rates). The non-synonymous mutations occurred in nine 

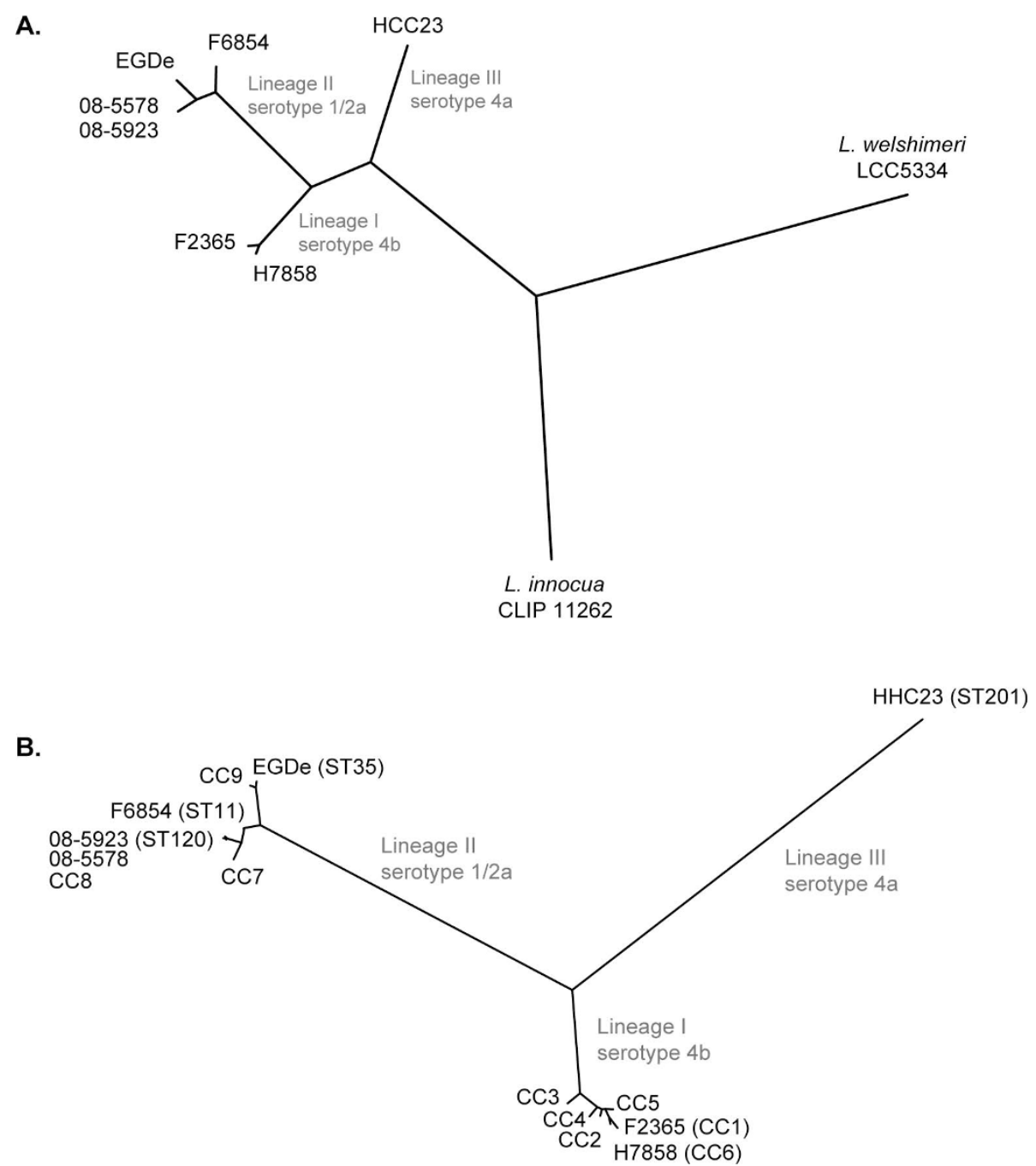

Figure 3 Maximum likelihood phylogenetic trees determined for Listeria genome sequences (A) and MLST loci (B). L. monocytogenes lineages and serotypes are indicated (grey text). 'CC' denotes clonal complexes and 'ST' denotes sequence types. Strain F2365 was isolated from a 1985 California cheese outbreak; H7858 from a 1998-9 Multistate hotdog oubreak; F6854 from a 1988 Oklahoma turkey hot dog sporadic case; EGDe is a laboratory strain passaged from an animal isolate from 1924.

COG categories, including four changes related to transcription, but no mutations occurred in COGs related to DNA repair, recombination or replication (Table 3). Only four non-synonymous changes represented functionally analogous amino acid changes (e.g, I/L/V/G) and none were in exported proteins carrying signal peptides. To place this finding into context, Listeria species have been reported as having the strongest purifying selection (elevated synonymous mutation rates) of all the prokaryotes following comparison of multiple completed genome sequences [37]. Furthermore, genome sequencing of four serotype 1/2a lineage II isolates from an endemic clone contaminating a single food production facility from 1988 to 2000 revealed only 11 total SNPs outside of the bacteriophage determinants, and a maximum of 8 SNPs were observed between any two given strains [12]. This low number of SNPs in an endemic clone spanning over 12 years suggested that noncontrolled natural populations of $L$. monocytogenes are stable and exhibit limited genetic micro-diversity [12]. If a similar mutation rate occurred in the serotype $1 / 2 \mathrm{a} L$. monocytogenes isolates recovered during this 2008 Canadian outbreak, passage of several decades would be expected in order to attain 28 total SNPs. We are assuming that 08-5923 shares a very recent ancestor as 08-5578 and thus speculate that 08-5923 was subjected to pressures resulting in elevated mutation rates and an abundance of non-synonymous changes.

We propose a model to describe the chromosomal evolution of strains involved in this nation-wide 

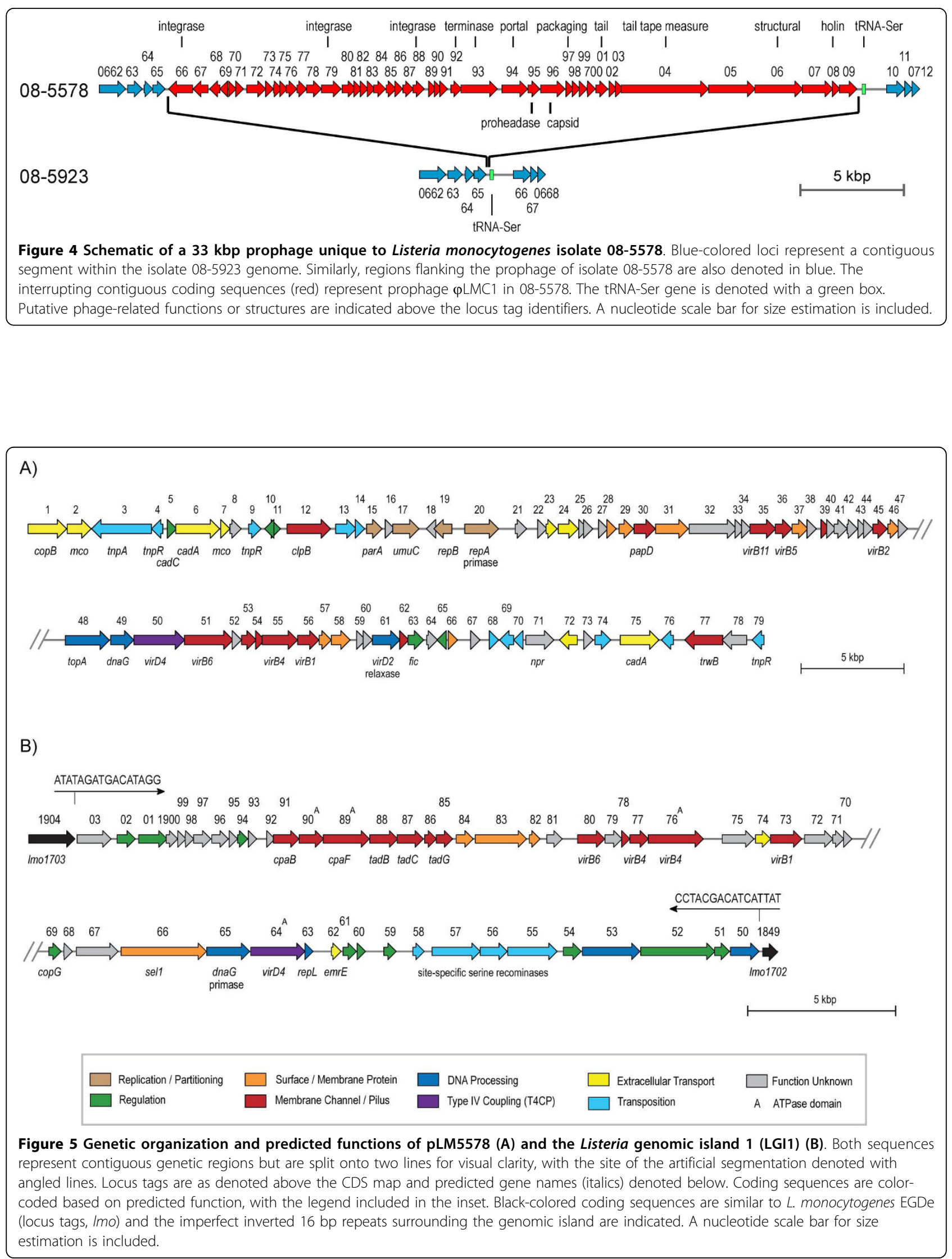
Table 3 Single nucleotide polymorphisms (SNPs) identified within chromosomal sequences of isolate 08-5923 relative to 08-5578.

\begin{tabular}{|c|c|c|c|c|c|c|c|c|c|}
\hline $\begin{array}{l}\text { SNP } \\
\text { position }\end{array}$ & CDS/Intergenic & gene & $\begin{array}{c}08-5578 \\
\text { sequence }\end{array}$ & $\begin{array}{c}08-5923 \\
\text { sequence }\end{array}$ & $\begin{array}{l}08-5578 \\
\text { codon }\end{array}$ & $\begin{array}{l}\text { 08-5923 } \\
\text { codon }\end{array}$ & $\begin{array}{l}08-5578 \\
\text { residue }\end{array}$ & $\begin{array}{l}08-5923 \\
\text { residue }\end{array}$ & Predicted Product \\
\hline 47737 & non-synonymous & & $\bar{T}$ & C & ATA & ACA & I & $T$ & hypothetical protein \\
\hline 113283 & non-synonymous & & $(\mathrm{G})$ & (A) & $(\mathrm{GAT})$ & (AAT) & D & $\mathrm{N}$ & ATP-binding cassette, subfamily B \\
\hline 172841 & synonymous & yaaQ & A & G & CCA & CCG & $P$ & $P$ & hypothetical protein \\
\hline 213957 & non-synonymous & fusA & $\mathrm{T}$ & A & $\pi \mathrm{TC}$ & TAC & $\mathrm{F}$ & Y & elongation factor $\mathrm{G}$ \\
\hline 291652 & non-synonymous & cytR & $\mathrm{T}$ & G & AGT & $A G G$ & S & $\mathrm{R}$ & transcriptional regulator, Lacl family \\
\hline 291653 & non-synonymous & cyt $R$ & G & $\mathrm{T}$ & GTG & TTG & V & L & transcriptional regulator, Lacl family \\
\hline 552482 & non-synonymous & $h s d R$ & C & G & TGC & TGG & C & W & type I restriction enzyme, R subunit \\
\hline 577443 & non-synonymous & celf & $A$ & G & GAC & GGC & D & G & 6-phospho-beta-glucosidase \\
\hline 630182 & non-synonymous & & C & A & ACA & AAA & $\mathrm{T}$ & K & hypothetical protein \\
\hline 833717 & non-synonymous & $\operatorname{araR}$ & (A) & $(\mathrm{T})$ & $(A A C)$ & (TAC) & N & Y & $\begin{array}{l}\text { arabinose operon transcriptional } \\
\text { repressor }\end{array}$ \\
\hline 850721 & intergenic & & G & C & & & & & \\
\hline 940888 & non-synonymous & pgcA & $A$ & G & GAA & GGA & $\mathrm{E}$ & G & phosphomannomutase \\
\hline 1076779 & synonymous & ykuQ & C & $\mathrm{T}$ & $\pi \mathrm{TC}$ & $\pi T$ & $\mathrm{~F}$ & $\mathrm{~F}$ & $\begin{array}{l}\text { Tetrahydrodipicolinate } \mathrm{N} \text { - } \\
\text { succinyltransferase }\end{array}$ \\
\hline 1096500 & non-synonymous & & $A$ & $\mathrm{~T}$ & ATA & TTA & 1 & L & hypothetical protein \\
\hline 1319530 & non-synonymous & & $\mathrm{T}$ & G & TGT & GGT & C & G & hypothetical protein \\
\hline 1462121 & non-synonymous & pta2 & C & $\mathrm{T}$ & GCT & $\mathrm{GTT}$ & A & V & phosphate butyryltransferase \\
\hline 1660409 & synonymous & hemL & (C) & $(\mathrm{G})$ & (CGC) & $(C G G)$ & $\mathrm{R}$ & $\mathrm{R}$ & $\begin{array}{l}\text { glutamate-1-semialdehyde } \\
\text { aminotransferase }\end{array}$ \\
\hline 1787404 & non-synonymous & & $\mathrm{T}$ & A & $\pi T$ & TTA & $\mathrm{F}$ & L & hypothetical protein \\
\hline 1901622 & non-synonymous & & $(\mathrm{T})$ & (C) & (GTA) & $(\mathrm{GCA})$ & V & A & $\begin{array}{l}\text { sigma-54 dependent transcriptional } \\
\text { regulator }\end{array}$ \\
\hline 1910870 & non-synonymous & & (C) & $(\mathrm{G})$ & (CGC) & (GGC) & $\mathrm{R}$ & G & hypothetical protein \\
\hline 2117257 & non-synonymous & $\operatorname{aroA}$ & $(\mathrm{T})$ & $(\mathrm{G})$ & (GTC) & $(G G C)$ & V & G & $\begin{array}{l}\text { 3-phosphoshikimate 1- } \\
\text { carboxyvinyltransferase }\end{array}$ \\
\hline 2124375 & non-synonymous & hept & (C) & $(\mathrm{T})$ & $(\mathrm{GCA})$ & (GTA) & A & V & trans-hexaprenyltranstransferase \\
\hline 2146277 & non-synonymous & punA & (A) & $(G)$ & (ATA) & $($ GTA) & । & V & purine-nucleoside phosphorylase \\
\hline 2261927 & intergenic & & C & A & & & & & \\
\hline 2404315 & non-synonymous & & G & A & AGT & AAT & S & $\mathrm{N}$ & hypothetical protein \\
\hline 2603164 & synonymous & & $(\mathrm{T})$ & $(\mathrm{G})$ & $(\mathrm{CTT})$ & $(\mathrm{CTG})$ & L & L & $\begin{array}{l}\text { D-methionine transport system } \\
\text { ATP-binding protein }\end{array}$ \\
\hline 2691224 & intergenic & & G & T & & & & & \\
\hline 2929661 & synonymous & $\operatorname{atp} A$ & (A) & (G) & (TCA) & $(\mathrm{TCG})$ & S & $S$ & $\begin{array}{l}\text { F-type } \mathrm{H}+\text {-transporting ATPase } \\
\text { alpha chain }\end{array}$ \\
\hline
\end{tabular}

SNP coordinates are in relation to the genome of 08-5578 and the nucleotide composition refers to the positive DNA strand unless the SNP lies within a coding sequence on the negative (complementary) strand, and in these instances are marked in brackets.

outbreak using the distribution and segregation of genetic traits such as SNPs, indels and prophage (Fig. 6). This model assumes that the last common ancestor (LCA) of all strains encoded wild type buk and gltX loci, $\varphi \mathrm{LMC1}$ was absent, and the wild type state of all SNP positions was represented by the sequences in 08-5578 with the exception of intergenic SNP at 2691224. Isolate 08-5923 is predicted to be a direct descendent of the LCA, as it is the only isolate encoding a wild type buk gene. The remainder of the LMACI.0001 isolates differed from the LCA by only the single frameshift in $b u k$, generating ancestor 2 (Fig. 6). From ancestor 2, acquisition of three independent traits $(\varphi \mathrm{LMC} 1$, the 21 bp deletion in $g l t X$ and the intergenic SNP at coordinate 2691224) occurred, resulting in a third lineage defined by the LMACI.0040 PFGE pattern. In light of the high numbers of non-synonymous SNPs in 08-5923 and macromolecular genetic changes such as bacteriophage integration in the lineage represented by $08-5578$, we speculate that three distinct, but highly related strains 


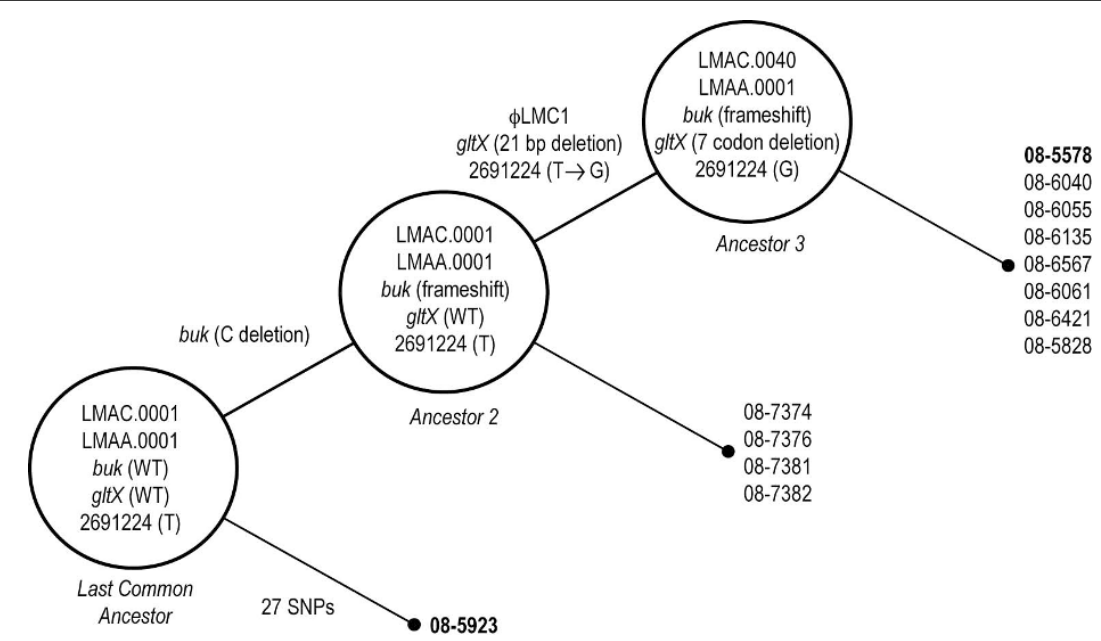

Figure 6 Evolutionary model for the Listeria monocytogenes isolates recovered during the $\mathbf{2 0 0 8}$ nation-wide foodborne outbreak Predicted mutational events are indicated on the diagonal lines, genotypes of the resulting lineages are denoted within circles, and isolates representative of those lineages are indicated to the right of solid dots. Sequenced isolates are denoted with bold text.

were circulating in this outbreak (Fig. 6). The diversifying SNPs in 08-5923 may have occurred in response to adverse environmental conditions prior to infection or host-specific conditions during infection, and $\varphi \mathrm{LMC1}$ likely arose by acquisition from other natural populations in the affected production facility.

\section{Genome sequence alignments reveal that the outbreak isolates belong to evolutionary lineage II - clonal complex 8}

Phylogenetic comparison to Listeria genome sequences representing each of the three $L$. monocytogenes evolutionary lineages, L. welshimeri and L. innocua indicated that 08-5578 and 08-5923 are both lineage II strains (Fig. 3A). The most closely related genome was strain EGDe, a serotype 1/2a lab-passaged animal isolate from 1924 [22]. For detection of large-scale genomic rearrangements, a dot plot comparison of 08-5578 versus the EGDe genome sequence was performed (see Additional file 3). This revealed that the common chromosomal sequences were collinear, with the exception of a large $50 \mathrm{kbp}$ inverted segment around the putative origin of replication (coordinate 1 of EGDe) (see Additional file 3). Symmetric inversions around the origin of replication have previously been observed between other bacterial genome sequences [38]. In contrast to only 28 SNPs being observed between 08-5578 and 08-5923, 24660 high quality SNPs and 941 estimated indels were revealed in a comparison of 08-5578 and EGDe (data not shown). These included 17874 synonymous SNPs, 4692 non-synonymous SNPs and 475 indels occurring within 1214 predicted coding sequences, with 1 to 167 non-synonymous SNPs and/or indels occurring per gene. Moreover, two large contiguous regions present in both 08-5578 and 08-5923 represent probable prophages (designated $\varphi \mathrm{LMC} 2$ and $\varphi \mathrm{LMC} 3$ ) that are absent in EGDe (Fig. 2, see Additional file 3). $\varphi$ LMC2 was highly related to phage $\mathrm{B} 025$, and $\varphi \mathrm{LMC} 3$ was inserted at comK and related to Listeria phage A006.

Comparative analysis of the regions used for multilocus sequence typing (MLST) indicated that isolates 085578 and 08-5923 are more closely related to lineage II clonal complex 8 (CC8) than to EGDe (Fig. 3B). The MLST determinants used by Ragon et. al. [24] were extracted in silico from the genome sequences and 085923 was identical to a previously characterized CC8, sequence type 120 (ST120) strain (encoding abcZ allele 5, bglA allele 6, cat allele 2, dapE allele 29, dat allele 5, $l d h$ allele $3, \operatorname{lh} k A$ allele 1$)$. The extracted sequences for 08-5578 were also identical to ST120 except for one SNP within the $a b c Z$ locus not currently listed in the Institute Pasteur's L. monocytogenes MLST database. The sole previous member of ST120 was identified as a clinical serotype $1 / 2 \mathrm{a}$ isolate derived from a CNS infection in New Zealand in 1995 [24]. Phylogenetic trees based on MLST and whole genome sequences were relatively congruent when considering evolutionary lineages, however genome sequences provide a more precise placement relative to other examined isolates. The pyrosequencing data also provided the opportunity to analyze the entire genome for micro and macro-diversity, including the full repertoire of phylogenetically relevant loci.

\section{Virulence-associated determinants of the outbreak isolates informs lineage- and strain-specific virulence potential}

The surface protein internalin, encoded by the inlA locus, is a principal virulence determinant promoting 
mammalian host cell invasion via interaction with Ecadherin on epithelial cells [39]. Truncation variants of inlA have been associated with decreased pathogenicity and significantly reduced invasiveness for human intestinal epithelial cells $[40,41]$. Using nomenclature assigned by Ragon et al. [24], isolates 08-5578 and 08-5923 both encode a full length inlA allele type 2 that has previously been observed in isolates related to human illness [24]. This singular determinant however cannot account for differences in pathogenicity since foodborne isolates have been observed with intact inlA loci [42] and inlA allele 2 is also encoded by environmental isolates [43]. L. monocytogenes does encode multiple additional internalin and internalin-like coding sequences, although the function of each paralog is currently unknown [21,44]. Isolates 08-5578 and 08-5923 both encode inlB, inlC, inlC2, inlD, inlE, inlF, inlG, inlI, inlJ and 11 other leucine-rich internalin-like coding sequences (see Additional file 4). The presence of an intact inlA locus and this compilation of other internalin-like loci may account in part for the pathogenicity of the serotype $1 / 2$ a outbreak strains sequenced in this study, but this requires further examination.

The Listeria pathogenicity island 1 (LIPI-1) encodes six significant virulence-associated loci: $\operatorname{prf} A$ (pleiotropic virulence transcriptional regulator), $p l c A$, $p l c B$ (both encoding phospholipases), hly (listeriolysin O), $m p l$ (metalloprotease) and act $A$ (involved in actin-mediated motility). Previous phylogenetic analysis of this region from food, clinical, animal and environmental isolates indicated that this gene cluster was genetically diverse and clustered based on the three L. monocytogenes evolutionary lineages $[25,45]$. BLASTn comparative analyses of this $\sim 9 \mathrm{kbp}$ region from 08-5578 and 08-5923 identified a very high sequence identity with other lineage II isolates, including $99.5 \%$ identity to the EDGe reference genome; $\geq 98 \%$ identity to all 23 lineage II isolates characterized by Ward et al. [25], and $\geq 98 \%$ nucleotide identity to all 21 lineage II isolates characterized by Orsi et al. [45]. In comparison, all LIPI-1 regions encoded by evolutionary lineage I and III strains in these previous studies were $\leq 95 \%$ identical to our lineage II strains.

PrfA regulates additional virulence determinants encoded elsewhere on the chromosome, such as $b s h$ encoding a bile salt hydrolase that promotes survival within the gut [46] and $u h p T$ encoding for a hexose phosphate permease for utilization of host carbon sources [47]. These latter two determinants were also encoded within 08-5578 and 08-5923. The presence of these determinants along with LIPI- 1 is well conserved across L. monocytogenes strains independent of evolutionary lineage, so are unlikely to enhance virulence potential unless the allelic diversity observed between lineages results in a phenotypic change. In general, the contribution of lineage-specific genome differences to virulence and pathogenicity of L. monocytogenes are not well understood. For example, recent in silico analyses have indicated that while there are lineage II-specific genomic regions not present in lineage I, their role in virulence is not clear [30]. Furthermore, the presence of the Listeria pathogenicity island LIPI-3 operon encoding Listeriolysin $S$ has been associated with evolutionary lineage I strains causing foodborne outbreaks [48]. This region was absent in the genomes of both 08-5578 and 08-5923.

\section{Outbreak isolates harbor a putative mobile genetic island} encoding translocation functions

A large $49.8 \mathrm{kbp}$ contiguous region (coordinates 1836435-1886209 of 08-5578; coding sequences LM5578_1850 to LM5578_1903) was present in both sequenced genomes yet absent in all publicly available Listeria genome sequences to date, including EGDe (Fig. 2). The bordering coding sequences LM5578_1849 and LM5578_1904 were each 98\% identical to contiguous EGDe coding sequences lmo1702 and lmo1703, respectively, implying that the $50 \mathrm{kbp}$ operon-like structured region represents a genomic insertion within the ancestral chromosome of these isolates. Accordingly, putative serine recombinases are encoded in this region (loci LM5578_1855-58) and 16 bp imperfect inverted repeats are present at the borders in the intergenic regions between loci 1849/50 and 1903/04 (Fig. 5B), indicating that this is a horizontally acquired genetic island, hereafter designated Listeria genomic island 1 (LGI1).

Coding sequences within LGI1 exhibited sequence homology and were similarly organized as contiguous regions present within several environmental firmicutes, including Clostridium kluyveri, C. bolteae and Desulfitobacterium hafniense. These LGI1-like regions also appeared to be horizontally-acquired, based on skewed G/C content relative to neighboring sequences [49]. The genetic organization and predicted functions of several LGI1 loci resembled the proposed $B$. anthracis pXO1 plasmid-encoded secretion system [50], including several coding sequences that resembled putative type II and type IV secretion systems (T4SS) (Fig. 5B; and Additional file 2). Prototypical members of these systems are involved in pilus biogenesis and translocation of DNAprotein complexes or virulence effectors, respectively. Canonical T4SS genes predicted within LGI1 include virB4, virD4, and virB11, which encode ATPases involved in substrate recruitment to the transfer complex and substrate translocation, and virB5 and virB6 subunit genes, which form the core membrane-spanning transfer complex (Fig. 5B; and Additional file 2). Genes that likely contribute to pilus-like surface appendages were also detected (cpa, tad), and the presence of a 
dnaG gene encoding a putative primase neighboring the virD4 coupling protein homolog suggests that this genetic island may be mobilizable (see Additional file 2). Besides pXO1, Type IV secretion-like systems (T4SLS) features have also been described in Gram-positive plasmids such as $B$. anthracis plasmid pXO2 [51,52] and the pheromone-inducible conjugative plasmid pCF10 of Enterococcus faecalis [53].

Gram-positive T4SLS also encode a putative peptidoglycan hydrolase and adhesin, both of which are predicted functions in LGI1 (LM5788_1873 and LM5578_1866, respectively). LM5788_1873 encodes a C-terminal NlpC/ P60 domain, and is predicted to be involved in assembly of the core substrate transfer complex as a VirB1-like peptidoglycan hydrolase. A P60 domain is also present in the autolytic virulence determinant designated Listeria invasion associated protein (Iap) [54]. LM5578_1866 is predicted to encode a Sel1-like repeat (SLR) family protein that contains helical domains mediating protein-protein interactions [55]. Although protein adhesins are often used in Gram-positive bacteria to mediate conjugative attachment to target cells, SLR proteins also are involved for eukaryotic cell entry by Legionella pneumophilia $[56,57]$. Whether this T4SLS is involved in translocation of pathogenicity effector molecule(s) (in addition to probable DNA-protein translocation) is tempting to speculate, but further study is required.

LGI1 also encoded a homolog (LM5578_1862) to the multidrug efflux proton:drug antiporter EmrE implicated in resistance to toxic cationic hydrophobic compounds such as quaternary ammonium compounds and tetracycline [58]. This gene was flanked by a MarR-family transcriptional regulator loci (1425) and a putative DNA-directed RNA polymerase sigma-24 subunit (rpoE, 1861) encoding a specialized ECF (extracytoplasmic function) family sigma factor, which is part of the bacterial stress response regulon [59]. A two component signal transduction system (sensor histidine kinase and response regulator; LM5578_1852 and 1851) and restriction modification components (LM5578_1850 and 1853) also were present. Cumulatively, LGI1 is unique compared to all currently sequenced L. monocytogenes but the contribution to pathogenicity or environmental persistence is unconfirmed.

\section{Conclusions}

High-throughput DNA sequencing rapidly provided the complete genetic content of two L. monocytogenes outbreak isolates. Within three days of project commencement, draft genome sequences were available that were suitable to begin comparative analyses such as genome alignments, preliminary annotation of coding sequences, and identification of traits associated with macro-diversity and micro-diversity. This allowed us to determine evolutionary lineages and unequivocally define the full breadth of genetic variation between two subtype variants identified by the internationally PulseNet standardized PFGE typing method. Whole genome sequencing therefore enabled robust real-time characterization of virulence determinants and genetic diversity (prophage and plasmid elements; SNP and indel mutations) within a natural L. monocytogenes population. These novel markers were then applied for a rapid assessment of the genetic relatedness of additional clinical, food, and environmental isolates recovered during the outbreak. The distribution of the SNP, indel and prophage traits indicated that three distinct but highly related strains were likely involved. Further characterization of the SNPs indicated that clinical isolate 08-5923 was likely subjected to positive selective pressures resulting in a higher frequency of non-synonymous mutation than would normally be expected for $L$. monocytogenes. Selective pressure for adaptive change could have resulted from host specific conditions during infection or adverse food storage conditions, but with only a single available isolate representative of this SNP genotype it is not possible to identify the micro-diversification timeline.

Previous comparative genomic studies of outbreakassociated L. monocytogenes have found several strain and serotype-specific coding sequences between serotype $4 \mathrm{~b}$ and $1 / 2 \mathrm{a}$ strains, but amongst these there were few relevant genetic traits suggestive of virulence potential $[21,30]$. One notable exception was variation in the complement of internalin-like coding determinants [21], and consistent with this finding, a large composition of internalin-like determinants was observed in the current study. In addition, there were two large-scale genetic insertions unique to our serotype $1 / 2 \mathrm{a}$ strains. Prophage $\varphi L M C 1$ was composed of genes related to previously characterized phage determinants, but on the whole, represented a novel Listeria phage. A $\sim 50 \mathrm{kbp}$ genetic island (LGI1) unique amongst all other currently sequenced L. monocytogenes isolates was also present in 08-5578, encoding putative translocation, resistance, and regulatory determinants.

While $L$. monocytogenes serotype $1 / 2$ a can be frequently isolated from food processing environments, the majority of invasive listeriosis outbreaks to date have resulted from lineage I serotype $4 \mathrm{~b}$ strains [15]. Lineage II serotype $1 / 2 \mathrm{a}$ strains have more frequently been associated with outbreaks of listerial gastroenteritis [15]. Our current study demonstrates that lineage II strains can also cause large outbreaks of severe invasive disease and is consistent with a global trend towards serotype $1 / 2$ a predominance. Whole genome sequencing allowed us to detect within these outbreak isolates a repertoire of genetic determinants involved in diversification and microevolution. These features may have a role in virulence and 
pathogenicity, as well as survival within food processing environments and in foods. Genomic studies can therefore facilitate a greater understanding of the lineage-specific and strain-specific features of L. monocytogenes and how they contribute to this pathogen's ecology and virulence. This knowledge may ultimately lead to the development of methods to better assess the risks posed by individual $L$. monocytogenes strains.

This study also provides a proof-of-concept that the latest generation DNA sequencing platforms have a place in real-time public health responses to bacterial pathogens. Whole genome sequencing may not be ready to be applied routinely as a subtyping method, but public health laboratories need to prepare for this inevitability and assess how to properly analyze and interpret whole genome sequences in the context of molecular epidemiology. Most of the current subtyping methods such as PFGE and MLST capture only a small proportion of the true genetic content, so it is still difficult to interpret robust data sets such as whole genomes when all previous characterizations have been comparatively limited in detail. It is foreseeable that the burgeoning capacity for whole genome sequencing will soon provide a cost effective alternative to the current subtyping methods after a reconciliation has been made between the true nature of subtypes, the diversity revealed by classical methods and the micro- and macro-diversity readily identified by next-generation sequencing technologies. As more genomes from clinical isolates are completed and compared (as in this study), it will become increasingly feasible to apply genome sequencing for responses to bacterial outbreaks.

\section{Methods}

\section{Bacterial isolates}

Clinical, food and environmental isolates (Table 1) were collected by the Ontario Central Public Health Laboratory and the Canadian Food Inspection Agency during an outbreak investigation of L. monocytogenes and transferred to the National Microbiology Laboratory (NML) for additional subtyping. The clinical isolates examined in this study were collected from individual outbreakassociated cases.

\section{Serotyping and Pulsed-field Gel Electrophoresis}

Serotyping was performed by slide agglutination with antisera prepared at the NML according to Seeliger and Höhne [60]. Molecular serotyping was completed using a multiplex PCR scheme [61]. Pulsed-field gel electrophoresis (PFGE) was performed according to the PulseNet standardized protocol using restriction enzymes $A s c \mathrm{I}$ and ApaI. PFGE patterns were designated using BioNumerics after comparison to the PulseNet Canada database.

\section{Genome sequencing and bioinformatics}

Genome sequencing was performed on the Roche GS $\mathrm{FLX}^{\mathrm{TM}}$ standard platform, as per the manufacturer's recommendations. The relative genome coverage achieved was approximately $40 \times$ for 08-5578 (Q40+ bases $=99.88 \%)$ and $36 \times$ for $08-5923(\mathrm{Q} 40+$ bases $=$ $99.91 \%)$. Within the $08-5578$ project the coverage of pLM5578 was $68 \times$, indicating that the plasmid copy number was between 1-2 copies per cell. De novo sequence assembly was completed using Roche's Newbler assembler and the Staden software package [62] after a fosmid mate-pair end library was constructed. Gap closure was completed by Sanger-based sequencing of select regions to bridge contigs. Presumptive insertion/deletions (indels) associated with homopolymeric regions were verified or corrected after Sanger-based sequencing of directed PCR amplicon templates generated from the corresponding regions in both 08-5578 and 08-5923 by proof-reading Taq polymerase. Sequences were deposited into GenBank under the accession numbers CP001602 (08-5578), CP001603 (pLM5578) and CP001604 (08-5923).

Pyrosequencing was completed within three days to provide greater than $99 \%$ of the genome coverage. This was sufficient for preliminary analysis such as identification of plasmid and phage determinants and candidate SNP's. Closed circular chromosomal sequences were obtained within an additional 5 weeks after fosmid libraries were constructed, contigs ordered and all gaps closed. Three additional weeks were required for resequencing of SNP and homopolymeric regions to confirm polymorphisms and indels between the two sequenced isolates. The costs associated with this project (in US dollars) were $\$ 5000$ for the GS-FLX run covering both isolates, $\$ 500 /$ isolate for the fosmid libraries and related consumables, and $\$ 2000$ / isolate for primer synthesis and Sanger-based sequencing for gap closure and resequencing.

Annotation of coding sequences for isolate 08-5578 was completed using GenDB v2.2 [63], BASys [64], Glimmer3 [65] and by comparison to RefSeq annotations completed for L. monocytogenes strain EGDe [22]. Sequences encoding rRNA and tRNA were identified by RNAmmer version 1.2 [66] and tRNAscan-SE version 1.23 [67], respectively. Artemis was used for manual annotation and additional manipulations [68]. Multiple sequence alignments of whole genomes and select loci were generated using MAUVE [69] and ClustalW [70], respectively, and maximum likelihood phylogenetic trees were generated using the Phylogeny Inference Package (Phylip version 3.68). Distant homologies between hypothetical coding sequences and entries at the PDB, COG, PFAM and SCOP databases were detected using the FFAS03 server [71]. Single nucleotide polymorphisms (SNPs) were identified between the sequenced 
isolates using NUCMER and dot plots were generated using MUMmerplot [72]. The circular representation of the genome of 08-5578 was created using DNAplotter [73] and feature tables generated using Artemis.

Reference Listeria genome sequences were obtained from GenBank for isolates EGDe (accession number NC_003210), F2365 (NC_002973), HCC23 (NC_011660), Clip11262 (NC_003212; L. innocua), SLCC5334 (NC_008555; L. welshimeri) and L. monocytogenes phage B025 (NC_009812). Accession numbers for plasmid DNA sequences of pLI100 and pXO2 were NC_003383 and NC_001496, respectively. In addition, the DNA sequences of L. monocytogenes strains F6854 and H7858 [21] and plasmid pLM80 from strain H7858 were obtained from the J. Craig Venter Institute Comprehensive Microbial Resource http://cmr.jcvi.org/cgibin/CMR/CmrHomePage.cgi. A cross match table (Additional file 5) of the coding sequences between all of these L. monocytogenes genomes was generated using the publically available annotations as of September $18^{\text {th }}, 2009$ with a reciprocal BLASTp alignment threshold of $80 \%$ identity and $80 \%$ hsp. Draft genomes sequences at the Broad Institute were also screened for select regions using BLAST available at their database http://www.broad.mit.edu/annotation/genome/listeria_group/MultiHome.html. MLST loci data were downloaded from the Institute Pasteur Listeria monocytogenes MLST Database http://www.pasteur.fr/recherche/genopole/PF8/mlst/Lmono.html.

\section{PCR screening and SNP confirmation}

All polymerase chain reactions were performed with Invitrogen HiFi Platinum proof-reading Taq polymerase following the manufacturer's directions, and with $1 \mathrm{uM}$ of each oligonucleotide (see Additional file 6) using the following thermocycling conditions: $94^{\circ} \mathrm{C}$ for 5 min.; 35 cycles of $94^{\circ} \mathrm{C}$ for $30 \mathrm{sec}$. $50^{\circ} \mathrm{C}$ for $30 \mathrm{sec}$. and $68^{\circ} \mathrm{C}$ for $45 \mathrm{sec}$; followed by $68^{\circ} \mathrm{C}$ for $5 \mathrm{~min}$. Amplicons were visualized after electrophoresis in $1 \%$ agarose-TBE gels. Confirmation of SNP sites was achieved by Sangerbased sequencing of targeted amplicons using the same oligonucleotides as used for PCR amplification.

Additional file 1: Identification of bacteriophage-related sequences in the putative prophage $\varphi \mathrm{LMC1}$.

Click here for file

[http://www.biomedcentral.com/content/supplementary/1471-2164-11120-S1.XLS ]

Additional file 2: Coding sequences on plasmid pLM5578 and the Listeria genetic island (LGI1) predicted to encode translocation

functions. FFAS03 scores above -9.0 are not significant, but three

predictions near this threshold were included.

Click here for file

[http://www.biomedcentral.com/content/supplementary/1471-2164-11120-S2.XLS ]
Additional file 3: Dot plot comparison of collinearity of Listeria monocytogenes genome 08-5578 relative to EGDe. Dots or lines represent segments of conservation between the two sequences. Blue lines represent collinear sequence similarities between the reverse complement of 08-5578 and EGDe and represent a symmetrical inversion around the origin of replication. Outlier dots indicate duplicated regions. A break in the main diagonal of a linear segment supports an insertion or deletion in either one of the sequences, and the associated features are identified with arrows ('LGI1', Listeria genomic island 1).

Click here for file

[http://www.biomedcentral.com/content/supplementary/1471-2164-11120-S3.TIFF ]

Additional file 4: Internalin and Internalin-like leucine rich coding sequences present in isolate 08-5578. The conserved LPXTG cell wall anchor domains were identified using HMMER TIGR01167.

Click here for file

[http://www.biomedcentral.com/content/supplementary/1471-2164-11120-S4.XLS]

Additional file 5: Cross-match table of all protein-encoding loci encoded by two serotype $1 / 2$ a outbreak-associated Listeria monocytogenes (08-5578 and 08-5923) versus other publically available, annotated $L$. monocytogenes genomes. Description and references are included in the Methods section.

Click here for file

[http://www.biomedcentral.com/content/supplementary/1471-2164-11120-S5.XLS]

Additional file 6: Oligonucleotides used in this study. All coordinates are in reference to the sequence of isolate $08-5578$.

Click here for file

[http://www.biomedcentral.com/content/supplementary/1471-2164-11120-S6.DOC ]

\section{Acknowledgements}

We thank the PulseNet Canada laboratory team (A. Desrochers, L. Tschetter, E. Ballegeer, and C. Munro), G. Peters, K. Melnychuk, C. Bonner, T. Murphy, A. Kearney, V. Wolf and M. Jerome for technical assistance; Canadian Food Inspection Agency Laboratories for food isolates; N. Thomson, D. Walker, M. He, A. Cerdeno-Tarraga, N. Croucher, T. Matthews, P. Mabon and T. Lawley for bioinformatic assistance; and F. Plummer, G. Glavin, M. Drebot, H. Tabor, C. Clark, D. Rasko, J. Farber, F. Pagotto and F. Jamieson for guidance during this study.

\section{Author details}

'National Microbiology Laboratory, Public Health Agency of Canada, Winnipeg, MB, Canada. ${ }^{2}$ Department of Medical Microbiology and Infectious Diseases, University of Manitoba, Winnipeg, MB, Canada. ${ }^{3}$ Public Health Laboratories, Ontario Agency for Health Protection and Promotion, Toronto, ON, Canada. ${ }^{4}$ Canadian Food Inspection Agency, Ottawa, ON, Canada.

\section{Authors' contributions}

Conceived and designed the experiments: MWG ST MG KT-Y OL GVD CN. Performed the experiments: ST KT-Y OL CN. Analyzed the data: MWG MG GVD ST HK KT-Y OL VA BA CN. Contributed reagents/materials/analysis tools: VA BA GVD HK. Wrote the paper: MWG MG GVD CN. Edited the manuscript: MWG ST MG GVD HK KT-Y OL VA BA CN. All authors read and approved the final manuscript.

Received: 30 June 2009

Accepted: 18 February 2010 Published: 18 February 2010

\section{References}

1. Seeliger HP: Listeriosis-history and actual developments. Infection 1988, 16(Suppl 2):S80-4.

2. Ivanek R, Grohn YT, Wiedmann M: Listeria monocytogenes in multiple habitats and host populations: review of available data for mathematical modeling. Foodborne Pathog Dis 2006, 3(4):319-336. 
3. Sauders BD, Durak MZ, Fortes E, Windham $K$, Schukken $Y$, Lembo AJ Jr, Akey B, Nightingale KK, Wiedmann M: Molecular characterization of Listeria monocytogenes from natural and urban environments. J Food Prot 2006, 69(1):93-105

4. Weis J, Seeliger HP: Incidence of Listeria monocytogenes in nature. Appl Microbiol 1975, 30(1):29-32.

5. Colburn KG, Kaysner CA, Abeyta C Jr, Wekell MM: Listeria species in a California coast estuarine environment. Appl Environ Microbio/ 1990, 56(7):2007-2011.

6. Mead PS, Slutsker L, Dietz V, McCaig LF, Bresee JS, Shapiro C, Griffin PM, Tauxe RV: Food-related illness and death in the United States. Emerg Infect Dis 1999, 5(5):607-625.

7. Lianou A, Sofos JN: A review of the incidence and transmission of Listeria monocytogenes in ready-to-eat products in retail and food service environments. J Food Prot 2007, 70(9):2172-2198.

8. Beresford MR, Andrew PW, Shama G: Listeria monocytogenes adheres to many materials found in food-processing environments. $J$ App/ Microbiol 2001, 90(6):1000-1005.

9. Walker SJ, Archer P, Banks JG: Growth of Listeria monocytogenes at refrigeration temperatures. J App/ Bacteriol 1990, 68(2):157-162.

10. Gandhi M, Chikindas ML: Listeria: A foodborne pathogen that knows how to survive. Int J Food Microbiol 2007, 113(1):1-15.

11. Wong AC: Biofilms in food processing environments. J Dairy Sci 1998, 81(10):2765-2770.

12. Orsi RH, Borowsky ML, Lauer P, Young SK, Nusbaum C, Galagan JE, Birren BW, Ivy RA, Sun Q, Graves LM, Swaminathan B, Wiedmann M: Shortterm genome evolution of Listeria monocytogenes in a non-controlled environment. BMC Genomics 2008, 9:539.

13. Tompkin RB: Control of Listeria monocytogenes in the food-processing environment. J Food Prot 2002, 65(4):709-725.

14. Wiedmann M: Molecular subtyping methods for Listeria monocytogenes. $J$ AOAC Int 2002, 85(2):524-531.

15. Swaminathan $B$, Gerner-Smidt P: The epidemiology of human listeriosis. Microbes Infect 2007, 9(10):1236-1243.

16. Miya S, Kimura B, Sato M, Takahashi H, Ishikawa T, Suda T, Takakura C, Fujii T, Wiedmann M: Development of a multilocus variable-number of tandem repeat typing method for Listeria monocytogenes serotype $4 \mathrm{~b}$ strains. Int J Food Microbiol 2008, 124(3):239-249.

17. Liu D: Identification, subtyping and virulence determination of Listeria monocytogenes, an important foodborne pathogen. J Med Microbiol 2006, 55(Pt 6):645-659.

18. Graves LM, Swaminathan B: PulseNet standardized protocol for subtyping Listeria monocytogenes by macrorestriction and pulsed-field gel electrophoresis. Int J Food Microbiol 2001, 65(1-2):55-62.

19. Mead PS, Dunne EF, Graves L, Wiedmann M, Patrick M, Hunter S, Salehi E, Mostashari F, Craig A, Mshar P, Bannerman T, Sauders BD, Hayes P, Dewitt W, Sparling P, Griffin P, Morse D, Slutsker L, Swaminathan B, Listeria Outbreak Working Group: Nationwide outbreak of listeriosis due to contaminated meat. Epidemiol Infect 2006, 134(4):744-751.

20. Pagotto F, Ng LK, Clark C, Farber J, Canadian Public Health Laboratory Network: Canadian listeriosis reference service. Foodborne Pathog Dis 2006, 3(1):132-137.

21. Nelson KE, Fouts DE, Mongodin EF, Ravel J, DeBoy RT, Kolonay JF, Rasko DA, Angiuoli SV, Gill SR, Paulsen IT, Peterson J, White O, Nelson WC, Nierman W, Beanan MJ, Brinkac LM, Daugherty SC, Dodson RJ, Durkin AS, Madupu R, Haft DH, Selengut J, Van Aken S, Khouri H, Fedorova N, Forberger H, Tran B, Kathariou S, Wonderling LD, Uhlich GA, Bayles DO, Luchansky JB, Fraser CM: Whole genome comparisons of serotype $4 \mathrm{~b}$ and $1 / 2 \mathrm{a}$ strains of the food-borne pathogen Listeria monocytogenes reveal new insights into the core genome components of this species. Nucleic Acids Res 2004, 32(8):2386-2395.

22. Glaser P, Frangeul L, Buchrieser C, Rusniok C, Amend A, Baquero F, Berche $P$, Bloecker H, Brandt P, Chakraborty T, Charbit A, Chetouani F, Couve E, de Daruvar A, Dehoux P, Domann E, Dominguez-Bernal G, Duchaud E, Durant L, Dussurget O, Entian KD, Fsihi H, Garcia-del Portillo F, Garrido P, Gautier L, Goebel W, Gomez-Lopez N, Hain T, Hauf J, Jackson D, Jones LM, Kaerst $U$, Kreft J, Kuhn M, Kunst F, Kurapkat G, Madueno E, Maitournam A, Vicente JM, Ng E, Nedjari H, Nordsiek G, Novella S, de Pablos B, Perez-Diaz JC, Purcell R, Remmel B, Rose M, Schlueter T, Simoes N, Tierrez A, Vazquez-Boland JA, Voss H, Wehland J, Cossart P: Comparative genomics of Listeria species. Science 2001, 294(5543):849-852.
23. Hain $T$, Steinweg $C$, Kuenne $C T$, Billion A, Ghai R, Chatterjee SS, Domann E, Karst U, Goesmann A, Bekel T, Bartels D, Kaiser O, Meyer F, Puhler A, Weisshaar B, Wehland J, Liang C, Dandekar T, Lampidis R, Kreft J, Goebel W, Chakraborty $\mathrm{T}$ : Whole-genome sequence of Listeria welshimeri reveals common steps in genome reduction with Listeria innocua as compared to Listeria monocytogenes. J Bacteriol 2006, 188(21):7405-7415.

24. Ragon M, Wirth T, Hollandt F, Lavenir R, Lecuit M, Le Monnier A, Brisse S: A new perspective on Listeria monocytogenes evolution. PLoS Pathog 2008, 4(9):e1000146.

25. Ward TJ, Gorski L, Borucki MK, Mandrell RE, Hutchins J, Pupedis K: Intraspecific phylogeny and lineage group identification based on the prfA virulence gene cluster of Listeria monocytogenes. J Bacteriol 2004, 186(15):4994-5002.

26. Wiedmann M, Bruce JL, Keating $C$, Johnson AE, McDonough PL, Batt CA Ribotypes and virulence gene polymorphisms suggest three distinct Listeria monocytogenes lineages with differences in pathogenic potential. Infect Immun 1997, 65(7):2707-2716.

27. Piffaretti JC, Kressebuch H, Aeschbacher M, Bille J, Bannerman E, Musser JM, Selander RK, Rocourt J: Genetic characterization of clones of the bacterium Listeria monocytogenes causing epidemic disease. Proc Natl Acad Sci USA 1989, 86(10):3818-3822.

28. Brosch R, Chen J, Luchansky JB: Pulsed-field fingerprinting of listeriae: identification of genomic divisions for Listeria monocytogenes and their correlation with serovar. App/ Environ Microbiol 1994, 60(7):2584-2592.

29. Graves LM, Swaminathan B, Reeves MW, Hunter SB, Weaver RE, Plikaytis BD, Schuchat A: Comparison of ribotyping and multilocus enzyme electrophoresis for subtyping of Listeria monocytogenes isolates. J Clin Microbiol 1994, 32(12):2936-2943.

30. Milillo SR, Badamo JM, Wiedmann M: Contributions to selected phenotypic characteristics of large species- and lineage-specific genomic regions in Listeria monocytogenes. Food Microbiol 2009, 26(2):212-223.

31. Chen Y, Ross WH, Gray MJ, Wiedmann M, Whiting RC, Scott VN: Attributing risk to Listeria monocytogenes subgroups: dose response in relation to genetic lineages. J Food Prot 2006, 69(2):335-344.

32. Sanger F, Nicklen S, Coulson AR: DNA sequencing with chain-terminating inhibitors. Proc Natl Acad Sci USA 1977, 74(12):5463-5467.

33. Medini D, Serruto D, Parkhill J, Relman DA, Donati C, Moxon R, Falkow S, Rappuoli R: Microbiology in the post-genomic era. Nat Rev Microbiol 2008, 6(6):419-430

34. Shendure J, Ji H: Next-generation DNA sequencing. Nat Biotechnol 2008, 26(10):1135-1145.

35. Mullapudi S, Siletzky RM, Kathariou S: Heavy-metal and benzalkonium chloride resistance of Listeria monocytogenes isolates from the environment of turkey-processing plants. Appl Environ Microbiol 2008, 74(5):1464-1468.

36. Kathariou S, Graves L, Buchrieser C, Glaser P, Siletzky RM, Swaminathan B: Involvement of closely related strains of a new clonal group of Listeria monocytogenes in the 1998-99 and 2002 multistate outbreaks of foodborne listeriosis in the United States. Foodborne Pathog Dis 2006, 3(3):292-302.

37. Novichkov PS, Wolf YI, Dubchak I, Koonin EV: Trends in prokaryotic evolution revealed by comparison of closely related bacterial and archaeal genomes. J Bacteriol 2009, 191(1):65-73.

38. Eisen JA, Heidelberg JF, White O, Salzberg SL: Evidence for symmetric chromosomal inversions around the replication origin in bacteria. Genome Biol 2000, 1(6):RESEARCH0011.

39. Vazquez-Boland JA, Kuhn M, Berche P, Chakraborty T, DominguezBernal G, Goebel W, Gonzalez-Zorn B, Wehland J, Kreft J: Listeria pathogenesis and molecular virulence determinants. Clin Microbiol Rev 2001, 14(3):584-640.

40. Jacquet C, Doumith M, Gordon Jl, Martin PM, Cossart P, Lecuit M: A molecular marker for evaluating the pathogenic potential of foodborne Listeria monocytogenes. J Infect Dis 2004, 189(11):2094-2100.

41. Nightingale KK, Windham K, Martin KE, Yeung M, Wiedmann M: Select Listeria monocytogenes subtypes commonly found in foods carry distinct nonsense mutations in inlA, leading to expression of truncated and secreted internalin $\mathrm{A}$, and are associated with a reduced invasion phenotype for human intestinal epithelial cells. Appl Environ Microbiol 2005, 71(12):8764-8772.

42. Handa-Miya S, Kimura B, Takahashi H, Sato M, Ishikawa T, Igarashi K, Fujii T: Nonsense-mutated inlA and prfA not widely distributed in Listeria 
monocytogenes isolates from ready-to-eat seafood products in Japan. Int J Food Microbiol 2007, 117(3):312-318.

43. Orsi RH, Ripoll DR, Yeung M, Nightingale KK, Wiedmann M: Recombination and positive selection contribute to evolution of Listeria monocytogenes in/A. Microbiology 2007, 153(Pt 8):2666-2678.

44. Jia Y, Nightingale KK, Boor KJ, Ho A, Wiedmann M, McGann P: Distribution of internalin gene profiles of Listeria monocytogenes isolates from different sources associated with phylogenetic lineages. Foodborne Pathog Dis 2007, 4(2):222-232.

45. Orsi RH, Maron SB, Nightingale KK, Jerome M, Tabor H, Wiedmann M: Lineage specific recombination and positive selection in coding and intragenic regions contributed to evolution of the main Listeria monocytogenes virulence gene cluster. Infect Genet Evol 2008, 8(5):566-576.

46. Dussurget $\mathrm{O}$, Cabanes D, Dehoux P, Lecuit M, Buchrieser C, Glaser P, Cossart $\mathrm{P}$, European Listeria Genome Consortium: Listeria monocytogenes bile salt hydrolase is a PrfA-regulated virulence factor involved in the intestinal and hepatic phases of listeriosis. Mol Microbiol 2002, 45(4):1095-1106.

47. Chico-Calero I, Suarez M, Gonzalez-Zorn B, Scortti M, Slaghuis J, Goebel W, Vazquez-Boland JA, European Listeria Genome Consortium: Hpt, a bacterial homolog of the microsomal glucose-6-phosphate translocase, mediates rapid intracellular proliferation in Listeria. Proc Natl Acad Sci USA 2002, 99(1):431-436.

48. Cotter PD, Draper LA, Lawton EM, Daly KM, Groeger DS, Casey PG, Ross RP, Hill C: Listeriolysin S, a novel peptide haemolysin associated with a subset of lineage I Listeria monocytogenes. PLoS Pathog 2008, 4(9): e1000144

49. Pundhir S, Vijayvargiya $H$, Kumar A: PredictBias: a server for the identification of genomic and pathogenicity islands in prokaryotes. In Silico Biol 2008, 8(3-4):223-234.

50. Grynberg M, Li Z, Szczurek E, Godzik A: Putative type IV secretion genes in Bacillus anthracis. Trends Microbiol 2007, 15(5):191-195.

51. Auwera Van der GA, Andrup L, Mahillon J: Conjugative plasmid pAW63 brings new insights into the genesis of the Bacillus anthracis virulence plasmid pXO2 and of the Bacillus thuringiensis plasmid pBT9727. BMC Genomics 2005, 6:103.

52. Auwera Van der GA, Timmery S, Mahillon J: Self-transfer and mobilisation capabilities of the pXO2-like plasmid pBT9727 from Bacillus thuringiensis subsp. konkukian 97-27. Plasmid 2008, 59(2):134-138.

53. Chen Y, Zhang X, Manias D, Yeo HJ, Dunny GM, Christie PJ: Enterococcus faecalis PcfC, a spatially localized substrate receptor for type IV secretion of the pCF10 transfer intermediate. J Bacteriol 2008, 190(10):3632-3645.

54. Schmid M, Walcher $M$, Bubert $A$, Wagner $M$, Wagner $M$, Schleifer KH: Nucleic acid-based, cultivation-independent detection of Listeria spp and genotypes of $L$ monocytogenes. FEMS Immunol Med Microbiol 2003, 35(3):215-225.

55. Mittl PR, Schneider-Brachert W: Sel1-like repeat proteins in signal transduction. Cell Signal 2007, 19(1):20-31.

56. Newton HJ, Sansom FM, Dao J, McAlister AD, Sloan J, Cianciotto NP, Hartland EL: Sel1 repeat protein LpnE is a Legionella pneumophila virulence determinant that influences vacuolar trafficking. Infect Immun 2007, 75(12):5575-5585.

57. Cirillo SL, Lum J, Cirillo JD: Identification of novel loci involved in entry by Legionella pneumophila. Microbiology 2000, 146(Pt 6):1345-1359.

58. Pornillos O, Chen YJ, Chen AP, Chang G: X-ray structure of the EmrE multidrug transporter in complex with a substrate. Science 2005, 310(5756):1950-1953.

59. Brooks BE, Buchanan SK: Signaling mechanisms for activation of extracytoplasmic function (ECF) sigma factors. Biochim Biophys Acta 2008, 1778(9):1930-1945.

60. Seeliger HPR, Höhne K: Serotyping of Listeria monocytogenes and related species. Methods in Microbiology London: Academic PressBergen T, Norris JR 1979, 13:31.

61. Doumith $M$, Buchrieser $C$, Glaser $P$, Jacquet $C$, Martin P: Differentiation of the major Listeria monocytogenes serovars by multiplex PCR. J Clin Microbiol 2004, 42(8):3819-3822.

62. Staden R, Beal KF, Bonfield JK: The Staden package, 1998. Methods Mol Biol 2000, 132:115-130

63. Meyer F, Goesmann A, McHardy AC, Bartels D, Bekel T, Clausen J, Kalinowski J, Linke B, Rupp O, Giegerich R, Puhler A: GenDB-an open source genome annotation system for prokaryote genomes. Nucleic Acids Res 2003, 31(8):2187-2195.

64. Van Domselaar GH, Stothard P, Shrivastava S, Cruz JA, Guo A, Dong X, Lu P, Szafron D, Greiner R, Wishart DS: BASys: a web server for automated bacterial genome annotation. Nucleic Acids Res 2005, , 33 Web Server: W455-9.

65. Delcher AL, Bratke KA, Powers EC, Salzberg SL: Identifying bacterial genes and endosymbiont DNA with Glimmer. Bioinformatics 2007, 23(6):673-679.

66. Lagesen $\mathrm{K}$, Hallin $\mathrm{P}$, Rodland $\mathrm{EA}$, Staerfeldt $\mathrm{HH}$, Rognes $\mathrm{T}$, Ussery DW: RNAmmer: consistent and rapid annotation of ribosomal RNA genes. Nucleic Acids Res 2007, 35(9):3100-3108.

67. Lowe TM, Eddy SR: tRNAscan-SE: a program for improved detection of transfer RNA genes in genomic sequence. Nucleic Acids Res 1997, 25(5):955-964.

68. Rutherford K, Parkhill J, Crook J, Horsnell T, Rice P, Rajandream MA, Barrell B: Artemis: sequence visualization and annotation. Bioinformatics 2000 16(10):944-945.

69. Darling AC, Mau B, Blattner FR, Perna NT: Mauve: multiple alignment of conserved genomic sequence with rearrangements. Genome Res 2004, 14(7):1394-1403.

70. Larkin MA, Blackshields G, Brown NP, Chenna R, McGettigan PA, McWilliam H, Valentin F, Wallace IM, Wilm A, Lopez R, Thompson JD, Gibson TJ, Higgins DG: Clustal W and Clustal X version 2.0. Bioinformatics 2007, 23(21):2947-2948.

71. Jaroszewski L, Rychlewski L, Li Z, Li W, Godzik A: FFAS03: a server for profile-profile sequence alignments. Nucleic Acids Res 2005, , 33 Web Server: W284-8.

72. Kurtz S, Phillippy A, Delcher AL, Smoot M, Shumway M, Antonescu C, Salzberg SL: Versatile and open software for comparing large genomes. Genome Biol 2004, 5(2):R12

73. Carver T, Thomson N, Bleasby A, Berriman M, Parkhill J: DNAPlotter: circular and linear interactive genome visualization. Bioinformatics 2009, 25(1):119-120.

doi:10.1186/1471-2164-11-120

Cite this article as: Gilmour et al:: High-throughput genome sequencing of two Listeria monocytogenes clinical isolates during a large foodborne outbreak. BMC Genomics 2010 11:120.

\section{Submit your next manuscript to BioMed Central and take full advantage of:}

- Convenient online submission

- Thorough peer review

- No space constraints or color figure charges

- Immediate publication on acceptance

- Inclusion in PubMed, CAS, Scopus and Google Scholar

- Research which is freely available for redistribution

Submit your manuscript at www.biomedcentral.com/submit
C Biomed Central 